\title{
Changes in blood pressure and sleep duration in patients with blue light-blocking/yellow-tinted intraocular lens (CHUKYO study)
}

\author{
Kazuo Ichikawa on behalf of the CHUKYO study investigators
}

\begin{abstract}
Blood pressure and sleep duration may be influenced by retinal light exposure. Cataracts may exert such an influence by decreasing the transparency of the crystalline lens. A large-scale clinical study was conducted to examine changes in blood pressure and sleep duration after intraocular lens (IOL) implantation during cataract surgery and to investigate how different types of IOL influence the degree of these effects. Using a questionnaire, we collected information, including blood pressure measurement and sleep duration, from 1367 patients (1367 eyes) before IOL implantation, 1 week after IOL implantation and 1 month after IOL implantation. Systolic and diastolic blood pressures were significantly decreased in the total patient group after implantation. The decrease in systolic blood pressure 1 month after implantation was significantly more in patients who received a yellow-tinted IOL than it was in those who received an ultraviolet (UV) light-filtering IOL. The post-implantation sleep duration, including naps, became shorter in patients who had slept too much and became longer in those who had slept too little before IOL implantation. Our observations suggest that a yellow-tinted IOL is better for patients with high blood pressure than a UV light-filtering IOL. Furthermore, the yellow-tinted IOL is as good as the UV light-filtering IOL for improving sleep duration. A pale yellow-tinted IOL is likely to be superior to a moderate yellow-tinted IOL in terms of allowing patients to discriminate different colors. Thus, the pale yellow-tinted IOL appears to be better for patients than the UV light-filtering IOL and the moderate yellow-tinted IOL.
\end{abstract}

Hypertension Research (2014) 37, 659-664; doi:10.1038/hr.2014.50; published online 13 March 2014

Keywords: blood pressure; blue light; cataract; intraocular lens; sleep

\section{INTRODUCTION}

In general, humans rely more heavily on vision than they do on their other senses. Thus, cataracts significantly impair quality of life. Cataracts not only make daily living activities difficult but can also exacerbate systemic conditions. These systemic conditions may simply be a result of deterioration due to aging because patients with cataracts are usually elderly and often have impaired activity levels and basal metabolisms; these metabolic disorders are associated with various comorbidities. However, a clinical study of 328 patients undergoing cataract surgery showed that their impaired sleep before surgery might have been improved postoperatively. ${ }^{1,2}$ The disturbances in their systemic conditions might have been caused by an anxious state and physical inactivity derived from poor vision, possibly affecting the autonomic nervous system and basal metabolism. However, light exposure itself can affect circadian rhythm, metabolic regulation, sleep patterns and autonomic nervous system functions such as heart rate variability, blood pressure and body temperature regulation. ${ }^{3-6}$ Sleep patterns are considered to be partially regulated by retinal photoreceptors, and cataracts can affect the systemic state through impaired light transmittance to the retina. ${ }^{7-9}$ Signals from retinal photoreceptors travel via the suprachiasmatic nucleus, hypothalamus and pineal body. ${ }^{10}$ The hypothalamus secretes several hormones that regulate the autonomic nervous system as well as endocrine and metabolic functions. ${ }^{11}$ The pineal body secretes melatonin, which regulates circadian rhythm. ${ }^{10}$ Production of melatonin is suppressed in bright environments and is increased in dim environments; ${ }^{12,13}$ therefore, the melatonin level itself has a circadian rhythm, with diurnal decrease and nocturnal increase. Exposure to bright light during daytime enhances the nocturnal elevation of melatonin levels in healthy subjects, although the exact mechanism of this increase is not well understood. ${ }^{14}$ Insomnia in the elderly was reported to possibly be improved by increasing melatonin levels. ${ }^{15}$ Administration of melatonin before bedtime reduces blood pressure in patients with untreated hypertension. ${ }^{16}$ Therefore, it is possible that improvement in the quality of light reaching the retina would improve melatonin secretion, circadian rhythm and systemic symptoms in patients with cataracts. Only a few small clinical studies have been carried out to test this hypothesis. Therefore, we conducted a largescale clinical study to examine changes in sleep duration and blood pressure after cataract surgery. 
In cataract surgery, intraocular lens (IOL) implantation is usually performed after removal of the natural crystalline lens. The firstgeneration IOLs allowed transmittance of full spectral electromagnetic waves including ultraviolet (UV) light, which covers a wavelength of $\sim 100-400 \mathrm{~nm}$ and is blocked by the natural lens. ${ }^{17} \mathrm{UV}$ light-filtering IOLs were developed after it became clear that the first IOLs were associated with an increased risk of postoperative cystoid macular edema. ${ }^{18-20}$ However, visible light with short wavelengths of 450 $495 \mathrm{~nm}$, so-called blue light, can also be harmful, causing retinal damage or impairing the function of the retina. ${ }^{21,22}$ Along with aging, the natural lens undergoes yellowing and its transmittance of blue light decreases. ${ }^{23}$ Therefore, the next generation of IOLs was designed to be yellowish and to filter blue light similar to an aged, natural lens. However, such blue light-filtering IOLs also contained potentially harmful properties. Melatonin secretion, which is the key factor in circadian rhythm regulation, is suppressed most strongly in response to blue light. ${ }^{8,13}$ Hence, the filtering of blue light could lead to unfavorable effects on sleep duration and the sleep cycle. ${ }^{24}$ However, there is a conflicting report that showed blue light filtering to have no effect on sleep. ${ }^{25}$ The effects of blue light filtering are even more controversial in terms of visual acuity, visual function and color vision in dim environments. ${ }^{26-38}$ Therefore, the newest generation of IOLs is tinted a paler shade of yellow to moderately filter blue light. $^{39-41}$ Currently, a variety of IOLs is available with different spectral transmittance properties; these new lenses are categorized as UV light-filtering or blue light-filtering (yellow-tinted) IOLs (Figure 1).

These differences affect the spectral properties of light reaching the retina. Whether these differences affect systemic conditions, such as sleep duration and blood pressure after cataract surgery, has not been adequately studied. Thus, we also focused on these issues in the present investigation.

\section{METHODS}

This study was conducted in accordance with the ethical principles in the Declaration of Helsinki and the Ethical Guideline for Clinical Research established by the Ministry of Health, Labor and Welfare of Japan. This study was conducted in an exploratory manner as a consecutive case series, and data were collected in 13 medical facilities related to Social Insurance Chukyo Hospital, Aichi, Japan, between 19 January 2006 and 8 February 2009. Patient information was collected by questionnaire after obtaining informed consent from those who received IOL implantation to treat cataracts. Clinical data included age, gender, systemic complications, systemic medications, type of IOL implanted, Standard Pseudoisochromatic Plates (SPP3) color vision test results and blood pressure and sleep duration (in $0.5 \mathrm{~h}$ units) before IOL implantation and at 1 week and 1 month after IOL implantation. The IOLs studied were categorized as yellow-tinted or UV light-filtering types. Yellowtinted IOLs were further categorized into pale yellow-tinted or moderate yellow-tinted types. The pale yellow-tinted IOLs were KS-AiN and KS-Ni (3step and 2-step pre-set injection systems, respectively, with the same lens model AQ-Ni, STAAR Japan, Urayasu, Chiba, Japan) and Avansee (lens model AN6K, Kowa Company, Nagoya, Aichi, Japan). The moderate yellow-tinted IOLs were Hoya AF-1 series (lens model FY-60AD, Y-60H and YA-60BBR, HOYA Corporation, Shinjuku, Tokyo, Japan) and Alcon AcrySof series (lens model SN60AT and SN60WF, Alcon Japan, Minato, Tokyo, Japan). Other lenses that can filter UV light, regardless of the manufacturer, were considered to be UV light-filtering IOLs.

The primary end points of the study were changes in blood pressure and sleep duration. Statistical analyses were conducted using Prism (GraphPad Software, San Diego, CA, USA). Categorical data representing the baseline patient characteristics were expressed as the number and percentage of patients with each characteristic. Continuous variables were expressed as the means \pm s.d. Differences in patient characteristics between groups were analyzed by applying analysis of variance or Pearson's $\chi^{2}$ test. The differences in blood pressure and sleep duration at 1 week and 1 month after IOL implantation $v s$. baseline and the changes between 1 week and 1 month after IOL implantation were analyzed using analysis of variance followed by a onesample $t$-test. For blood pressure, the changes were analyzed according to subgroups of patients with or without high blood pressure. High blood pressure was defined as systolic blood pressure (SBP) of $140 \mathrm{~mm} \mathrm{Hg}$ or higher and/or diastolic blood pressure (DBP) of $90 \mathrm{~mm} \mathrm{Hg}$ or higher before IOL implantation. Patients without high blood pressure were defined as those not meeting either criterion for high blood pressure. For sleep duration, changes were analyzed according to subgroups of patients with sleep durations of $6 \mathrm{~h}$ or less, between 6.5 and $8 \mathrm{~h}$, or $8.5 \mathrm{~h}$ or more. These effects were compared among the three types of IOLs. If necessary, analysis of covariance was used to adjust for baseline value differences. The results of the SPP3 color vision test were analyzed as the rates of correct answers, compared among the three types of

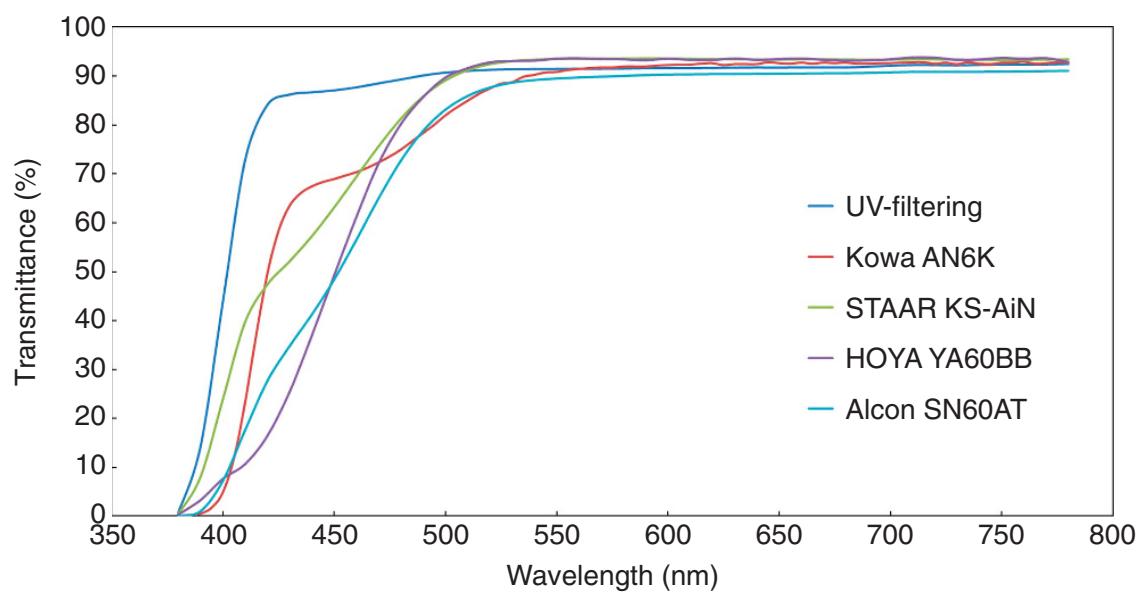

Figure 1 Spectral transmittance properties of several types of IOLs. The pale yellow-tinted IOLs (moderately filtering blue light) used in the patients in this study were KS-AiN and KS-Ni (STAAR Japan) and AN6K (Kowa Company). KS-AiN and KS-Ni are 3-step and 2-step pre-set injection systems, respectively, with the same lens model AQ-Ni. The moderate yellow-tinted IOLs (further filtering blue light) were FY-60AD, Y-60H and YA-60BBR (HOYA Corporation) and SN60AT and SN60WF (Alcon Japan). YA-60BB (not used in this study) and SN60AT are the examples of the moderate yellow-tinted IOLs by HOYA and Alcon, respectively. The others have slightly different but similar spectral transmittance properties in terms of those for wavelength of $400-450$ nm. All of the other lenses filtering UV light (wavelength $<400 \mathrm{~nm}$ ) were considered to be UV light-filtering IOLs regardless of the manufacturer. The line of UVfiltering in Figure 1 is an example of those. 
IOLs in 5-year age groups, from 20 to 95 years old, using analysis of variance and Student's $t$-test. All statistical tests were two-sided, and $P$-values $<0.05$ were interpreted as being statistically significant.

\section{RESULTS}

Patient characteristics are shown in Table 1. Patient information was collected for 1367 eyes in 1367 patients, of whom 40.0\% were male and $54.4 \%$ had undergone IOL implantation in the right eye. The mean \pm s.d. for age was $70.1 \pm 8.4$ years. Of the entire patient population, $65.3 \%$ were reported as those with hypertension. The SBP was $136.9 \pm 21.1 \mathrm{~mm} \mathrm{Hg}$ and the DBP was $78.0 \pm 13.5 \mathrm{~mm} \mathrm{Hg}$; $23.9 \%$ were taking anti-hypertensive agents; and $47.5 \%$ had high blood pressure no matter whether they were taking anti-hypertensive agents or not-that is, SBP $\geqslant 140 \mathrm{~mm} \mathrm{Hg}$ and/or DBP $\geqslant 90 \mathrm{~mm} \mathrm{Hg}$, before IOL implantation. Regarding other systemic complications, $15.6 \%$ of patients had diabetes mellitus, $13.8 \%$ had dyslipidemia and $11.6 \%$ had cardiovascular disease. Patient sleep duration was $7.1 \pm 1.4$ h. Patients received different types of IOL: 704 patients received pale yellow-tinted IOLs, 355 received moderate yellow-tinted IOLs and 308 received UV light-filtering IOLs. There were more males in the pale yellow-tinted IOL group $(P=0.0211)$. The patients in the moderate yellow-tinted IOL group were older than those in the other groups $(P=0.0029)$. The UV light-filtering IOL group included more diabetic patients $(P=0.0033)$ and more patients with cardiovascular disease $(P=0.0337)$.

Compared with the baseline values, the mean blood pressure of the entire patient population decreased significantly at 1 week and 1 month after IOL implantation (Figure 2). The decrease in the mean blood pressure was greater in patients with high blood pressure, whereas patients without high blood pressure before IOL implantation showed a slight increase (Figure 3). When the effects on blood pressure levels were compared by type of IOL, the mean changes in SBP at 1 month after IOL implantation were $-3.0 \pm 20.5 \mathrm{~mm} \mathrm{Hg}$ in patients with UV light-filtering IOLs and $-5.4 \pm 19.8 \mathrm{~mm} \mathrm{Hg}$ in those with yellow-tinted IOLs. The difference between these two groups was statistically significant (Figure 4). The decrease in SBP did not differ significantly between patients with pale yellow-tinted and moderate yellow-tinted IOLs (data not shown).
The mean changes in DBP were $-1.2 \pm 12.7 \mathrm{~mm} \mathrm{Hg}$ in patients with UV light-filtering IOLs and $-1.9 \pm 13.3 \mathrm{~mm} \mathrm{Hg}$ in those with yellow-tinted IOLs, and these differences were not significant (data not shown).

The effect of IOL implantation on sleep duration, including naps, was also investigated. The mean sleep duration did not change in patients who slept between 6 and $8 \mathrm{~h}$ per day. However, the mean sleep duration after IOL implantation approached $6 \mathrm{~h}$ in patients whose preoperative durations had been $6 \mathrm{~h}$ or less (Figure 5), and the mean sleep duration approached $8 \mathrm{~h}$ in those whose preoperative durations had been $8.5 \mathrm{~h}$ or more (Figure 6). These effects did not differ according to the type of IOL.

Among the three types of IOLs, SPP3 color vision test results demonstrated that patients with pale yellow-tinted IOLs made the fewest errors (Figure 7). Patients with UV light-filtering IOLs made a modest number of errors, and those with moderate yellow-tinted IOLs made the most errors.

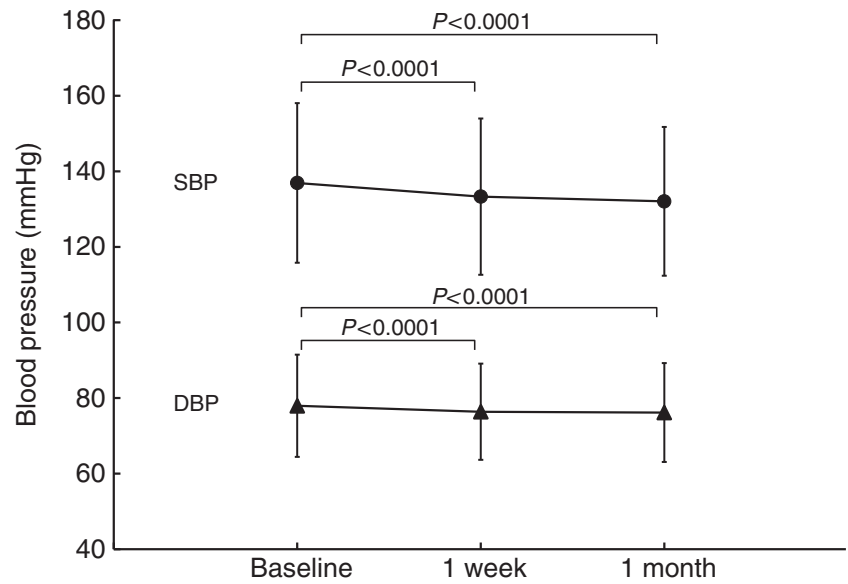

Figure 2 Changes in blood pressure from the baseline after IOL implantation in the entire patient population $(n=1367)$. $P$-values shown are from $t$-tests for differences from baseline. $P$-values from analyses of variance for differences among baseline, 1 week and 1 month after cataract surgery are $<0.0001$ for SBP and 0.0005 for DBP.

Table 1 Patient background

\begin{tabular}{|c|c|c|c|c|c|}
\hline & Total & Pale yellow & Moderate yellow & UV & P-value \\
\hline Right eye & $743(54.4 \%)$ & $395(56.1 \%)$ & $190(53.5 \%)$ & $158(51.3 \%)$ & 0.3446 \\
\hline Age, y & $70.1 \pm 8.4$ & $69.6 \pm 8.4$ & $71.4 \pm 7.7$ & $69.8 \pm 9.0$ & 0.0029 \\
\hline Hypertension & $893(65.3 \%)$ & $457(64.9 \%)$ & $234(65.9 \%)$ & $202(65.6 \%)$ & 0.9436 \\
\hline Diabetes mellitus & $213(15.6 \%)$ & 89 (12.6\%) & 60 (16.9\%) & $64(20.8 \%)$ & 0.0033 \\
\hline Anti-hypertensive & 327 (23.9\%) & $168(23.9 \%)$ & $89(25.1 \%)$ & $70(22.7 \%)$ & 0.7787 \\
\hline $\mathrm{SBP}, \mathrm{mmHg}$ & $136.9 \pm 21.1$ & $137.1 \pm 21.2$ & $136.6 \pm 22.2$ & $137.1 \pm 19.7$ & 0.9544 \\
\hline $\mathrm{DBP}, \mathrm{mmHg}$ & $78.0 \pm 13.5$ & $78.1 \pm 13.6$ & $77.5 \pm 14.0$ & $78.1 \pm 12.7$ & 0.7757 \\
\hline $\mathrm{SBP} \geqslant 140 / \mathrm{DBP} \geqslant 90$ & $650(47.5 \%)$ & $316(44.9 \%)$ & $176(49.6 \%)$ & $158(51.3 \%)$ & 0.1151 \\
\hline Sleep duration, $\mathrm{h}$ & $7.1 \pm 1.4$ & $7.0 \pm 1.4$ & $7.1 \pm 1.5$ & $7.2 \pm 1.4$ & 0.1414 \\
\hline
\end{tabular}

Abbreviations: ANOVA, analysis of variance; DBP, diastolic blood pressure; moderate yellow, moderate yellow-tinted intraocular lens; Pale yellow, pale yellow-tinted intraocular lens; SBP, systolic blood pressure; UV, ultraviolet light-filtering intraocular lens.

Age, SBP, DBP and sleep duration are indicated as mean \pm s.d. and others as the number (\%).

$P$-values shown are from ANOVA or Pearson's $\chi^{2}$ test in comparison among three IOL groups.

aNo subject was reported for both eyes implanted. 


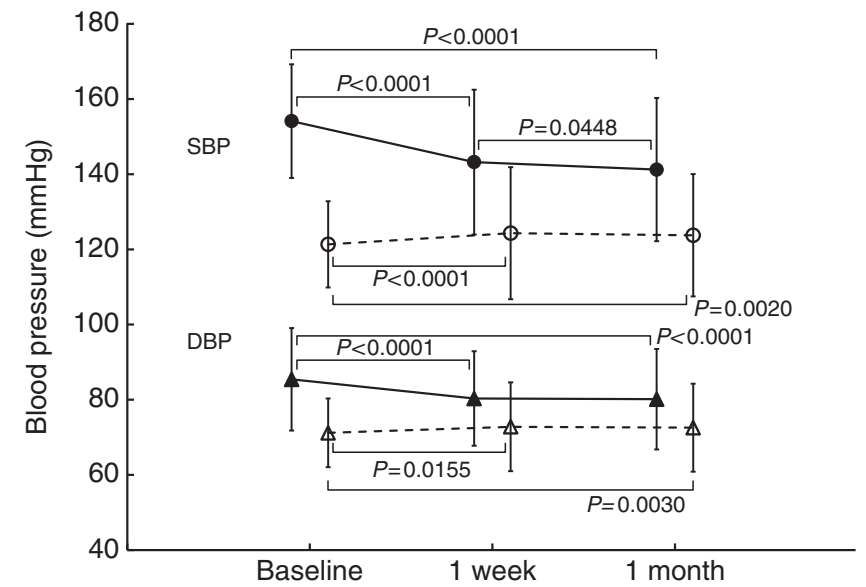

Figure 3 Changes in blood pressure from the baseline after $\mathrm{IOL}$ implantation in patients with and without high blood pressure $(n=650$ and 717). Closed or open symbols indicate data of patients with or without high blood pressure, respectively. $P$-values shown are from $t$-tests for differences from baseline. $P$-values from analyses of variance for differences among baseline, 1 week and 1 month after cataract surgery are $<0.0001$ for SBP and DBP in patients with high blood pressure and 0.0005 for SBP and 0.0100 for DBP in those without high blood pressure.

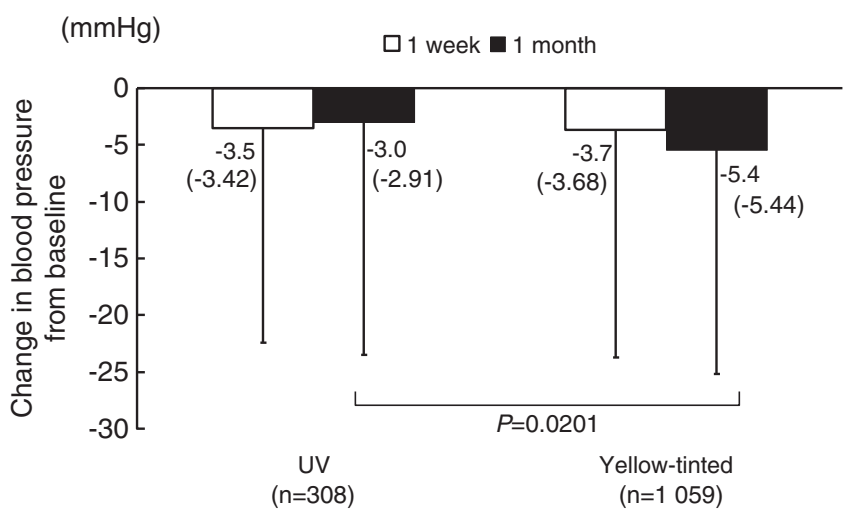

Figure 4 Changes in systolic blood pressure after cataract surgery in patients with UV light-filtering and yellow-tinted IOL. $P$-values shown are from analyses of covariance with the baseline as covariate. Least square means are expressed in parentheses.

\section{DISCUSSION}

Cataract patients may have systemic abnormalities involving control of body temperature and melatonin secretion as well as abnormal sleep duration and blood pressure due to dysfunctional light transmission to the retina through the crystalline lens. ${ }^{1-16}$ This research confirmed that such systemic disturbances, which might be caused by cataracts, showed improvement after cataract surgery in a large number of patients. These improvements might be attributable to the acquisition of clear vision, amelioration of anxiousness or gains made in daily living activities, which may result in favorable autonomic nervous system and basal metabolism consequences. However, improvements in the quality of light might also be among the mechanisms that ameliorate the aforementioned conditions. ${ }^{1-16}$ Although there were no significant differences in vision among the IOL groups after cataract surgery, there were differences in outcomes among the groups, implying that the difference in spectral transmittance properties might have resulted

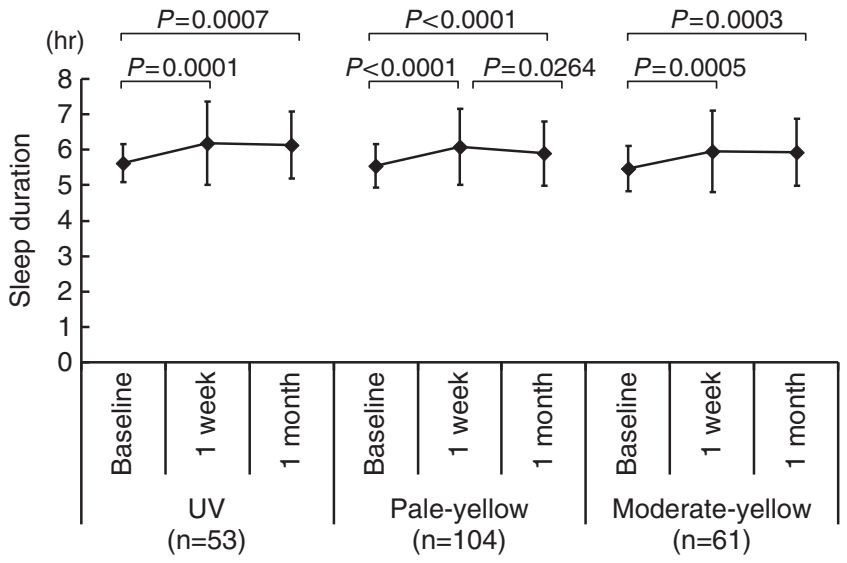

Figure 5 Changes in sleep duration after cataract surgery according to the types of IOLs in patients who slept $6 \mathrm{~h}$ or less including naps. $P$-values shown are from $t$-tests for differences from baseline. $P$-values from analyses of variance for the differences among baseline, 1 week and 1 month after cataract surgery are 0.0002 for UV light-filtering IOL, 0.0002 for moderate yellow-tinted IOL and $<0.0001$ for pale yellow-tinted IOL.

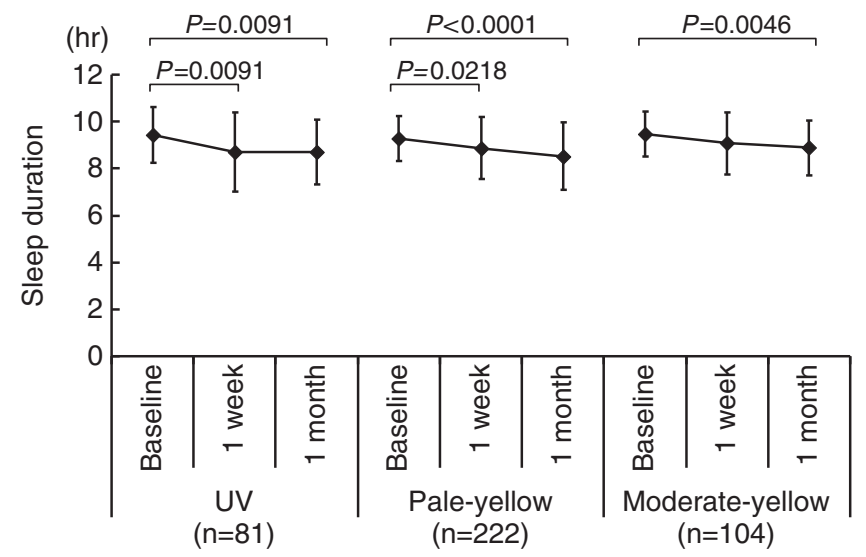

Figure 6 Changes in sleep duration after cataract surgery according to the types of IOLs in patients who slept $8.5 \mathrm{~h}$ or more including naps. $P$-values shown are from $t$-tests for differences from baseline. $P$-values from analyses of variance for differences among baseline, 1 week and 1 month after cataract surgery are 0.0109 for UV light-filtering IOL, 0.0152 for moderate yellow-tinted IOL and 0.0001 for pale yellow-tinted IOL.

in different effects on the autonomic nervous system and melatonin secretion.

The decrease in SBP was greater in patients with yellow-tinted IOLs than in those with UV light-filtering IOLs. This may be because blood pressure is known to increase with blue light exposure in people with normal blood pressure. ${ }^{42,43}$ Thus, blue light, which was not filtered by UV light-filtering IOLs, may counteract the blood pressure reduction after IOL implantation. It is possible that the changes in DBP did not differ between patients with UV light-filtering IOLs and those with blue light-filtering IOLs owing to the advanced ages of our subject population, as the mean was 70.1 years old. The elderly population has a lower DBP than the younger population because of their reduced arterial wall compliance, which should minimize the differences in DBP changes caused by different types of IOLs.

Sleep duration became shorter in patients who slept too much and became longer in those who slept too little, suggesting that sleep duration was improved by IOL implantation. There were no 


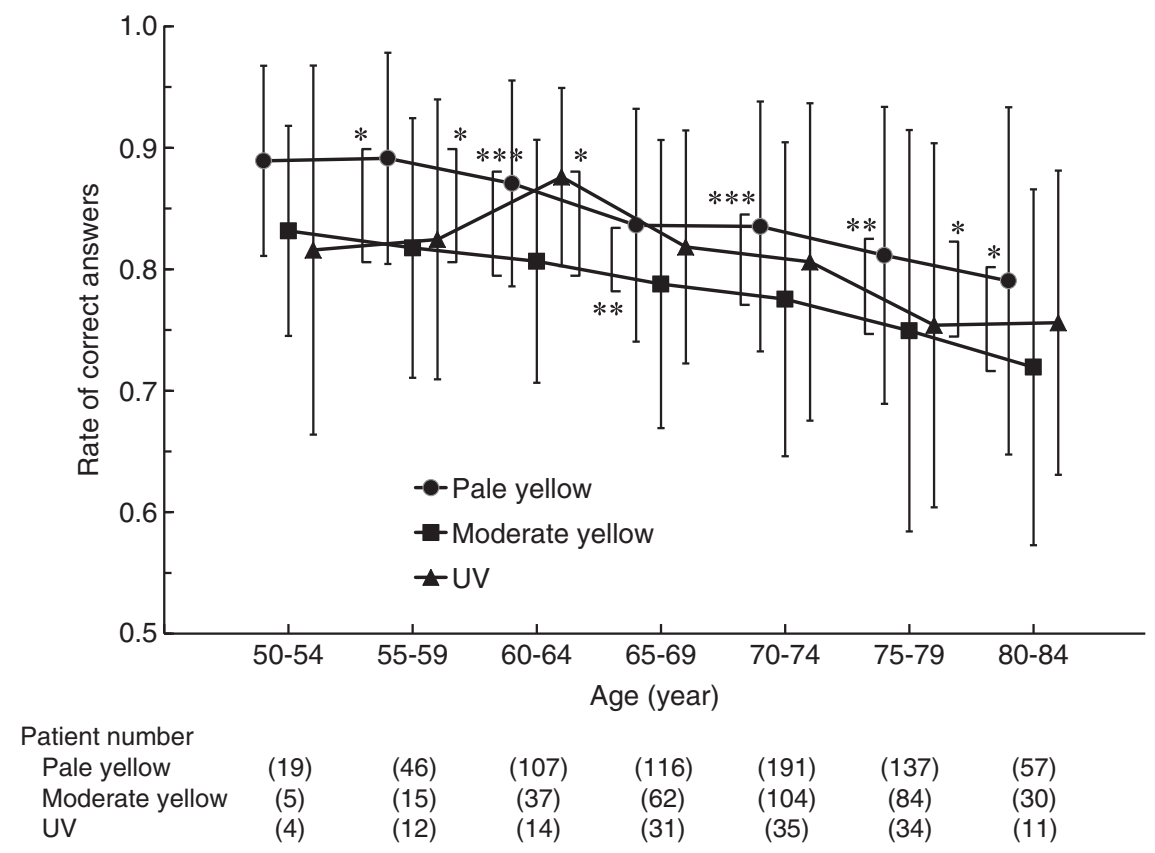

Figure 7 Rates of correct answers in SPP3 test according to the types of IOLs. $P$-values show are from $t$-tests for differences between the types. ${ }^{*} P<0.05$, $* * P<0.01$ and ${ }^{* * *} P<0.001$.

differences in these effects among any of the types of IOLs used. Although the effects of UV light filtering and blue light filtering on sleep are controversial, ${ }^{24,25,38}$ it is at least noteworthy that blue lightfiltering IOLs were associated with an improvement in sleep duration similar to that achieved with UV light-filtering IOLs.

It has been reported that color vision in patients with blue lightfiltering IOLs did not differ from patients with UV light-filtering IOLs. ${ }^{30-35}$ However, the scores on the SPP3 test, which is a different method from the tests used in the aforementioned reports, differed according to the type of IOL. There might be differences in the perception of color vision among tested patients according to the type of IOL implanted. Such differences might have affected the mood status of our subjects, leading to variable degrees of blood pressure change. However, there was no consistent relationship between the changes in blood pressure and the SPP3 test results. Further studies are needed to elucidate whether changes in blood pressure and other systemic conditions after cataract surgery are attributable to changes in color vision or non-visual effects. As the natural crystalline lens becomes yellowish with aging, ${ }^{23}$ patients with UV light-filtering IOLs, which are not tinted yellow, often report that their color vision changes after cataract surgery. However, patients with moderate yellow-tinted IOLs have color vision close to what they had before cataract development. As for improving color vision to the normal level, a pale yellow-tinted IOL, which shows the best results on the SPP3 test, is considered to be a good option.

Not only was improvement of sleep duration after IOL implantation observed, as has already been reported, but blood pressure reduction was also documented in this study. Yellow-tinted IOLs appeared to make a greater contribution to blood pressure reduction than UV light-filtering IOLs in patients with high blood pressure and to improve sleep duration to an extent similar to that of UV lightfiltering IOLs. In addition, pale yellow-tinted IOLs appeared to be superior to moderate yellow-tinted IOLs in terms of distinguishing colors and are the best option among yellow-tinted IOLs.

\section{CONFLICT OF INTEREST}

The authors declare no conflict of interest.

\section{ACKNOWLEDGEMENTS}

I acknowledge the contributions of the CHUKYO study investigators for data collection: Motohiro Hoshino, M.D., Ph.D. (Hoshino Eye Clinic), Miyoko Kato, M.D., Ph.D. (Kato-Eye Clinic), Kazuteru Kojima, M.D., Ph.D. (Kojima Eye Clinic), Takashi Kojima, M.D., Ph.D. (Hachiman Hospital), Naohisa Naito, M.D. (Chukyo Eye Clinic), Kimitoshi Nakamura, M.D., Ph.D. (Nakamura Eye Clinic), Satoru Oshika, M.D., Ph.D. (Oshika Eye Clinic), Yutaka Saito, M.D. (Saito Eye Clinic), Yuya Satoh, M.D., Ph.D. (Satoh Yuya Eye Clinic), Noriyasu Shiroyama, M.D., Ph.D. (Tomita Eye Clinic), Takashi Uezumi, M.D. (Kaibana Ganka Clinic), Yohei Yokoyama, M.D. (Nishikani Eye Clinic).

1 Asplund R, Lindblad BE. The development of sleep in persons undergoing cataract surgery. Arch Gerontol Geriatr 2002; 35: 179-187.

2 Asplund R, Lindblad BE. Sleep and sleepiness 1 and 9 months after cataract surgery. Arch Gerontol Geriatr 2004; 38: 69-75.

3 Czeisler CA, Allan JS, Strogatz SH, Ronda JM, Sánchez R, Ríos CD, Freitag WO, Richardson GS, Kronauer RE. Bright light resets the human circadian pacemaker independent of the timing of the sleep-wake cycle. Science 1986; 233: 667-671.

4 Badia P, Myers B, Boecker M, Culpepper J, Harsh JR. Bright light effects on body temperature, alertness, EEG and behavior. Physiol Behav 1991; 50: 583-588.

5 Boivin DB, Duffy JF, Kronauer RE, Czeisler CA. Dose-response relationships for resetting of human circadian clock by light. Nature 1996; 379: 540-542.

6 Broadway J, Arendt J. Delayed recovery of sleep and melatonin rhythms after nightshift work in Antarctic winter. Lancet 1986; 2: 813-814.

7 Berson DM, Dunn FA, Takao M. Phototransduction by retinal ganglion cells that set the circadian clock. Science 2002; 295: 1070-1073.

8 Brainard GC, Hanifin JP, Greeson JM, Byrne B, Glickman G, Gerner E, Rollag MD. Action spectrum for melatonin regulation in humans: evidence for a novel circadian photoreceptor. J Neurosci 2001; 21: 6405-6412.

9 Schmidt TM, Do MT, Dacey D, Lucas R, Hattar S, Matynia A. Melanopsin-positive intrinsically photosensitive retinal ganglion cells: from form to function. $J$ Neurosci 2011; 31: 16094-16101.

10 Ibata Y, Okamura H, Tanaka M, Tamada Y, Hayashi S, Iijima N, Matsuda T, Munekawa K, Takamatsu T, Hisa Y, Shigeyoshi Y, Amaya F. Functional morphology of the suprachiasmatic nucleus. Front Neuroendocrinol 1999; 20: 241-268.

11 Kalsbeek A, Fliers E. Daily regulation of hormone profiles. Handb Exp Pharmacol 2013; 217: 185-226. 
12 Lewy AJ, Wehr TA, Goodwin FK, Newsome DA, Markey SP. Light suppresses melatonin secretion in humans. Science 1980; 210: 1267-1269.

13 Herljevic M, Middleton B, Thapan K, Skene DJ. Light-induced melatonin suppression: age-related reduction in response to short wavelength light. Exp Gerontol 2005; 40: 237-242.

14 Takasu NN, Hashimoto S, Yamanaka Y, Tanahashi Y, Yamazaki A, Honma S, Honma K. Repeated exposures to daytime bright light increase nocturnal melatonin rise and maintain circadian phase in young subjects under fixed sleep schedule. Am J Physiol Regul Integr Comp Physiol 2006; 291: R1799-R1807.

15 Olde Rikkert MG, Rigaud AS. Melatonin in elderly patients with insomnia. A systematic review. Z Gerontol Geriatr 2001; 34: 491-497.

16 Scheer FA, Van Montfrans GA, van Someren EJ, Mairuhu G, Buijs RM. Daily nighttime melatonin reduces blood pressure in male patients with essential hypertension. Hypertension 2004; 43: 192-197.

17 Mainster MA. Spectral transmittance of intraocular lenses and retinal damage from intense light sources. Am J Ophthalmol 1978; 85: 167-170.

18 Ham Jr WT, Mueller HA, Sliney DH. Retinal sensitivity to damage from short wavelength light. Nature 1976; 260: 153-155.

19 Mainster MA. Solar retinitis, photic maculopathy and the pseudophakic eye. J Am Intraocul Implant Soc 1978; 4: 84-86.

20 Ham Jr WT, Ruffolo Jr JJ, Mueller HA, Guerry D 3rd. The nature of retinal radiation damage: dependence on wavelength, power level and exposure time. Vision Res 1980; 20: 1105-1111.

21 Hafezi F, Marti A, Munz K, Remé CE. Light-induced apoptosis: differential timing in the retina and pigment epithelium. Exp Eye Res 1997; 64: 963-970.

22 Grimm C, Wenzel A, Williams T, Rol P, Hafezi F, Remé C. Rhodopsin-mediated bluelight damage to the rat retina: effect of photoreversal of bleaching. Invest Ophthalmol Vis Sci 2001; 42: 497-505.

23 Boettner EA, Wolter JR. Transmission of the macular media. Invest Ophthalmol Vis Sci 1962; 1: 776-783.

24 Kessel L, Siganos G, Jørgensen T, Larsen M. Sleep disturbances are related to decreased transmission of blue light to the retina caused by lens yellowing. Sleep 2011; 34: 1215-1219.

25 Landers JA, Tamblyn D, Perriam D. Effect of a blue-light-blocking intraocular lens on the quality of sleep. J Cataract Refract Surg 2009; 35: 83-88.

26 Zhu XF, Zou HD, Yu YF, Sun Q, Zhao NQ. Comparison of blue light-filtering IOLs and UV light-filtering IOLs for cataract surgery: a meta-analysis. PLOS One 2012; 7: e33013.

27 Schwiegerling J. Blue-light-absorbing lenses and their effect on scotopic vision. J Cataract Refract Surg 2006; 32: 141-144.
28 Werner JS. Night vision in the elderly: consequences for seeing through a "blue filtering' intraocular lens. Br J Ophthalmol 2005; 89: 1518-1521.

29 Kiser AK, Deschler EK, Dagnelie G. Visual function and performance with blue-light blocking filters in age-related macular degeneration. Clin Experiment Ophthalmol 2008; 36: 514-520.

30 Kara-Júnior N, Jardim JL, de Oliveira Leme E, Dall'Col M, Susanna Jr R. Effect of the AcrySof Natural intraocular lens on blue-yellow perimetry. J Cataract Refract Surg 2006; 32: 1328-1330.

31 Landers J, Tan TH, Yuen J, Liu H. Comparison of visual function following implantation of Acrysof Natural intraocular lenses with conventional intraocular lenses. Clin Experiment Ophthalmol 2007; 35: 152-159.

32 Marshall J, Cionni RJ, Davison J, Ernest P, Lehmann R, Maxwell WA, Solomon K. Clinical results of the blue light-filtering AcrySof Natural foldable acrylic intraocular lens. J Cataract Refract Surg 2005; 31: 2319-2323.

33 Raj SM, Vasavada AR, Nanavaty MA. AcrySof Natural SN60AT versus AcrySof SA60AT intraocular lens in patients with color vision defects. J Cataract Refract Surg 2005; 31 2324-2328.

34 Rodríguez-Galietero A, Montés-Micó R, Muñoz G, Albarrán-Diego C. Blue-light filtering intraocular lens in patients with diabetes: contrast sensitivity and chromatic discrimination. J Cataract Refract Surg 2005; 31: 2088-2092.

35 Yuan Z, Reinach P, Yuan J. Contrast sensitivity and color vision with a yellow intraocular len. Am J Ophthalmol 2004; 138: 138-140.

36 Brockmann C, Schulz M, Laube T. Transmittance characteristics of ultraviolet and blue-light-filtering intraocular lenses. J Cataract Refract Surg 2008; 34: 1161-1166.

37 Henderson BA, Grimes KJ. Blue-blocking IOLs: a complete review of the literature. Surv Ophthalmol 2010; 55: 284-289.

38 Mainster MA. Violet and blue light blocking intraocular lenses: photoprotection versus photoreception. Br J Ophthalmol 2006; 90: 784-792.

39 van de Kraats J, van Norren D. Sharp cutoff filters in intraocular lenses optimize the balance between light reception and light protection. J Cataract Refract Surg 2007 33: 879-887.

40 Mainster MA. Intraocular lenses should block UV radiation and violet but not blue light. Arch Ophthalmol 2005; 123: 550-555.

41 Mainster MA, Sparrow JR. How much blue light should an IOL transmit? $\mathrm{Br} \mathrm{J}$ Ophthalmol 2003; 87: 1523-1529.

42 Kobayashi H, Sato M. Physiological responses to illuminance and color temperature of lighting. Ann Physiol Anthropol 1992; 11: 45-49.

43 Yasukouchi A, Ishibashi K. Non-visual effects of the color temperature of fluorescent lamps on physiological aspects in humans. J Physiol Anthropol Appl Human Sci 2005; 24: $41-43$. 